\title{
Does Tourism Cause Growth Asymmetrically in a Panel of G-7 Countries? A Short Note
}

\author{
Abdulnasser Hatemi- ${ }^{1 *}$, Rangan Gupta ${ }^{2}$, Axel Kasongo ${ }^{2}$, Thabo Mboweni ${ }^{2}$, \\ Ndivhuho Netshitenzhe ${ }^{2}$
}

\author{
${ }^{1}$ Economics and Finance Department, United Arab Emirates University, Al Ain, United Arab Emirates \\ ${ }^{2}$ Department of Economics, University of Pretoria, Pretoria 0002, South Africa \\ *Correspondence author: Abdulnasser Hatemi-J \\ ahatemi@uaeu.ac.ae
}

\begin{abstract}
:
We analyse whether tourism (measured by real tourism receipts) causes growth in an asymmetric fashion in a panel of G-7 countries over the period of 1995-2014. Our results reveal that the tourism-led growth hypothesis holds for France, Germany, and the US, with negative tourism shocks being more important for Germany, Italy, Japan, while positive shocks are more important in UK and the US. Our results imply that, policy makers in Germany, Italy and Japan should be more concerned when tourism receipts decline.
\end{abstract}

Keywords: Economic growth, Tourism receipts, G7, Asymmetric panel causality test JEL Classifications: F43, E01; C32

\section{Introduction}

Tourism has emerged as an important sector in the world economy, with globalisation increasing the number of tourist visits around the world. Not only has tourism contributed 9.5 per cent of total global GDP but it has also contributed 8.9 per cent of total global employment in 2013 (World Travel and Tourism Council, 2014).

Hence, not surprisingly, the literature on the tourism-led growth hypothesis (TLGH) is huge, to say the least. ${ }^{1}$ Upon reading the TLGH literature, we find that there is well-documented evidence of tourism to have played an important role in the economic development of

\footnotetext{
* We would like to thank two anonymous referees for many helpful comments. However, any remaining errors are solely ours.

${ }^{1}$ Balaguer and Cantavella-Jorda (2002), Gunduz and Hatemi-J (2005) and Oh (2005) were among the original studies to investigate the relationship between tourism and economic growth. For detailed literature review on this hypothesis, the reader is referred to Arslanturk et al., (2011), Balcilar et al., (2014) and Antonakakis et al., $(2015 a, b)$. For a recent literature review on the tourism-led growth hypothesis see Brida et al. (2016).
} 
emerging and lower income countries. Indeed, research on the TLGH does exist for the developed world as well (see for example Antonakakis et al., (2015a, b)). However,when compared to the number of studies dealing with developing economies, relatively lesser research has been done to analyse the effect of tourism on the economic growth of developed countries. This is primarily because there are well-established reasons based on technological progress which is believed to be the main driver of economic growth in developed countries. Having said this, the effects of tourism on developed countries should be considered in detail as well, given the fact that 65.46 per cent of total tourism receipts in 2014 went to developed countries $^{2}$. Therefore, the aim of this paper is to assess, for the first time, to the best of our knowledge, the asymmetric causal impact of tourism activity on the economic performance of G-7 countries (Canada, France, Germany, Italy, Japan, the UK and the US), using an asymmetric panel causality test suggested by Hatemi-J (2011) and Hatemi-J et al. (2016), over the period of 1995-2014. These countries are of particular interest not only because they have well developed tourist infrastructure, but also because 5 of these 7 countries are part of the top 10 tourism destinations by international tourism receipts in 2014; the exception being Canada (17th) and Japan (14th), which features in the top 20 (Bloom Consulting, 2014-2015; United Nations World Tourism Organization (UNWTO), 2015).

Such an analysis will provide evidence of whether TLGH is valid for the above-mentioned countries. Note that, the standard method for causality assumes that the causal impact of positive change is the same as the causal impact of a negative change in the absolute terms. However, this might be a too restrictive assumption because in the reality there might be an asymmetric causal impact. For example, it is widely agreed that people react more to negative news than the positive ones (Hatemi-J et al., 2016). Given this, our approach of asymmetric causality will also help in analysing whether the causal effect of tourism shocks (positive and negative) are asymmetric or not, which has greater implications for policymaking. Such information will allow policymakers to set policy and allocate resources in a more focused manner, concentrating on the tourism shock that most affects economic performance. Further, unlike some panel data-based papers, this paper does not look at the aggregate (pooled) effect of tourism activity on economic growth but analyses the relationship of these two variables for each country (by controlling for cross-sectional error dependence), even when being in a panel set-up to accommodate the short length of the time-series. This allows for the analysis to be heterogenous and prevents policymakers from implementing a 'one size fits all' policy that may have unintended consequences for those countries that may not exhibit the same relationship as the pooled case.

\footnotetext{
${ }^{2}$ The figure is calculated using data from the annual report of UNWTO in 2015. World tourism receipts in 2014 were US\$1245 billion and tourism receipts in the advanced economies for that year was US\$815 billion.
} 
The rest of the paper is organised as follows: Section 2 describes the methodology used. Section 3 presents the data and shows the empirical results and their interpretation. The last section provides a summary and concludes.

\section{Methodology}

There are a number of tests that have been developed in the literature in order to test for Granger (1969) causality within a panel system. However, these tests do not allow for asymmetric causal effects. Recently, Hatemi-J (2011) and Hatemi-J et al. (2016) have suggested an asymmetric panel causality test, which is used in this study. We are interested in finding out whether or not an increase in tourism receipts will cause an increase in economic growth. Similarly, it is important to find how economic growth is affected by a decrease in tourism receipts. The test is implemented within a panel system which combines the crosssectional and the time series dimensions. It also allows for dependency across cross-sectional units, which results in more efficiency compared to the standard methods. The test is discussed formally below.

Assuming (which we also confirm below using formal statistical tests of unit root) that both Gross Domestic Product (GDP) and the variable that measures the impact of tourism (tourism receipts) are integrated of order 1 variables, each can be presented by follows. According to Hatemi-J (2011), any variable in the panel system that is integrated if the first degree can be expressed as the following:

$$
y_{i 1, t}=y_{i 1, t-1}+e_{i 1, t}=y_{i 1,0}+\sum_{j=1}^{t} e_{i 1, j}
$$

For $i=1, \ldots, 7$. The denotation $e$ is a white noise error term. The innovations can be defined as $e_{i 1, t}^{+}:=\max \left(e_{i 1, t}, 0\right)$, and $e_{i 1, t}^{-}:=\min \left(e_{i 1, t}, 0\right)$. By using definitions we can present the cumulative partial sums of the changes, i.e. $y_{i 1, t}^{+}$and $y_{i 1, t}^{-}$as the following:

$$
\begin{gathered}
y_{i 1, t}^{+}=y_{i 1,0}^{+}+e_{i 1, t}^{+}=y_{i 1,0}+\sum_{j=1}^{t} e_{i 1, j}^{+} \\
y_{i 1, t}^{-}=y_{i 1,0}^{-}+e_{i 1, t}^{-}=y_{i 1,0}+\sum_{j=1}^{t} e_{i 1, j}^{-}
\end{gathered}
$$


Assuming that we are interested in testing for causality between the positive components, then the following vector autoregressive seemingly unrelated regression model of order $p$, $\operatorname{VAR}-\operatorname{SUR}(p)$ can be estimated:

$$
\left[\begin{array}{l}
y_{i 1, t}^{+} \\
y_{i 2, t}^{+}
\end{array}\right]=\left[\begin{array}{l}
\beta_{i 0} \\
\gamma_{i 0}
\end{array}\right]+\left[\begin{array}{ll}
\sum_{r=1}^{p} \beta_{i 1, r} & \sum_{r=1}^{p} \beta_{i 2, r} \\
\sum_{r=1}^{p} \gamma_{i 1, r} & \sum_{r=1}^{p} \gamma_{i 2, r}
\end{array}\right] \times\left[\begin{array}{l}
y_{i 1, t-r}^{+} \\
y_{i 2, t-r}^{+}
\end{array}\right]+\left[\begin{array}{c}
\varepsilon_{i 1, t}^{+} \\
\varepsilon_{i 2, t}^{+}
\end{array}\right]
$$

The error terms in the system are defined by $\varepsilon_{i 1, t}^{+}$and $\varepsilon_{i 2, t}^{+}$. Note that these error terms can be correlated across cross-section units. The lag order $p$ is determined by minimizing a panel version of an information criterion suggested by Hatemi-J (2003, 2008).

The null hypothesis that $y_{i 2, t}^{+}$does not cause $y_{i 1, t}^{+}$for the cross sectional unit $i$ in the panel is defined as

$H_{0}: \beta_{i 2, r}=0, \forall r$. Where $r=1, \ldots, p$.

This null hypothesis can be tested by using a Wald test. Note that it is possible to conduct causality tests between negative components, i.e., $\left(y_{i 1, t}^{-}, y_{i 2, t}^{-}\right)$, in a similar way.

Note that, since our analysis is based on a panel SUR approach, and we use bootstrap to obtain critical values of each cross-section members comprising the panel, we do not need to ensure whether the two variables are stationary if used in first-differenced form, or account for cointegration, if we use them in levels. In our case, we consider log-levels of the variables, and the bootstrapped Wald test used in the analysis still holds, irrespective of cointegration or not. As Kónya (2006) suggests, this approach does not require joint hypotheses for all panel members, but allows for contemporaneous correlation across them, making it possible to exploit the extra information provided by the panel data setting. In addition, apart from the lag structure, there is no need for pretesting.

So to summarize, this methodology transforms the variables of concern (in our case GDP and tourism receipts) into their positive and negative components in order to test for asymmetric causal impacts. By using this methodology we can determine what happens to economic growth if tourism receipts increase and compare it to the case when tourism receipts decrease. 


\section{Data and empirical results}

This section presents the results from the procedure described above to assess the relationship between tourism activity on the economic performance of G-7 countries. The data used for this study is annual and covers the period from 1995 to 2014. The sample period has been decided purely by data availability on the measure for tourism activity. All variables are used in their natural logarithmic form. The data used are real GDP (at constant 2005 US dollars) to measure economic performance and real international tourism receipts (at constant 2005 US dollars) to measure the tourism performance for each country, and are sourced from the

Figure 1: Annual Real GDP and Real Tourism Receipts of G-7 countries for 1995-2014

a. Natural Logarithm of Real GDP

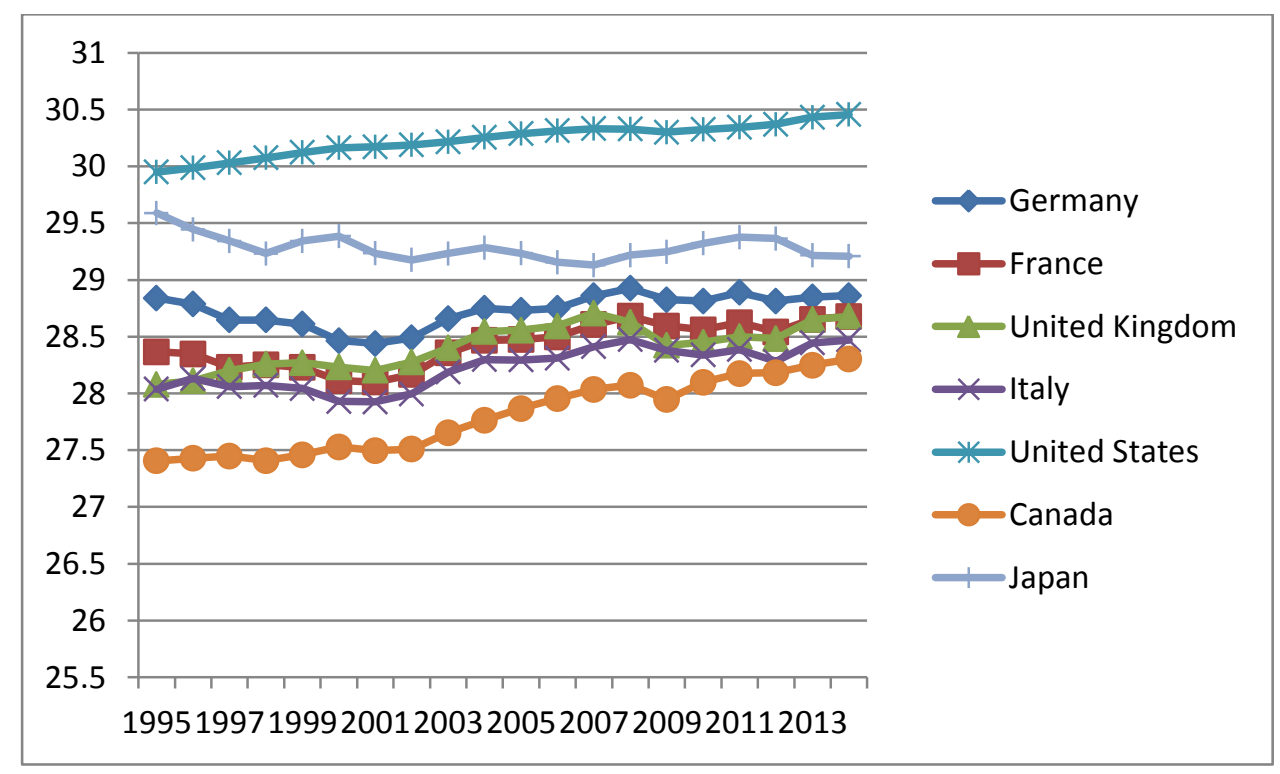

b. Natural Logarithm of Real Tourism Receipts

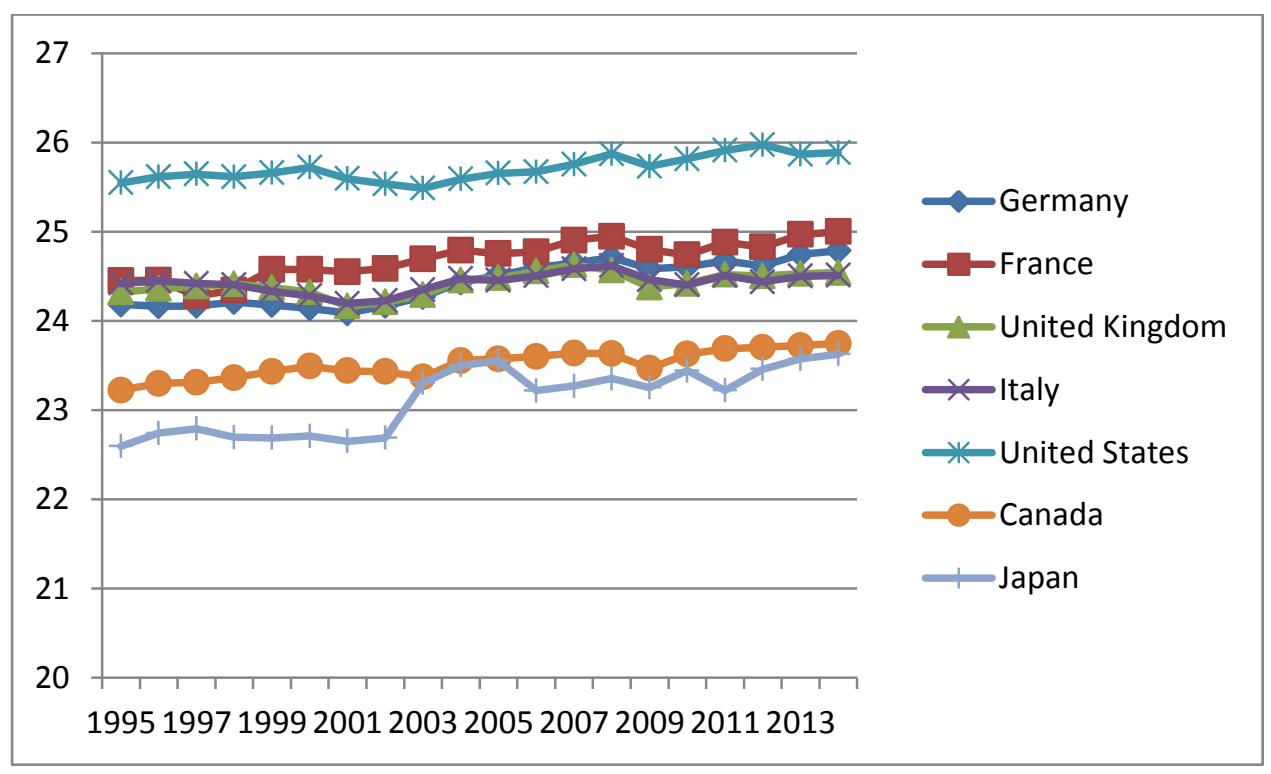


World Bank's World Development Indicators. ${ }^{3}$ Figure 1 presents a graphical illustration of the two series. On average, summary statistics revealed that Japan had the highest growth rate and volatility in terms of real tourism receipts, while Italy had the lowest growth rate and Germany the lowest volatility. If we compared the growth rate of tourism receipts between 1995 and 2014, Japan was found to have witnessed the highest growth rate in tourism receipts, while Italy had the lowest growth rate over the corresponding period. In terms of number of tourist arrivals, Japan was again found to have the highest growth rate and volatility, while Canada had the lowest growth rate and France the lowest volatility. When we compared the growth rate of tourist arrivals between 1995 and 2014, again Japan showed up as the country with the highest growth rate, and Canada as the one with the lowest growth rate. $^{4}$

Besides the many technical advantages of our approach discussed in the introduction, recall that, an additional feature of our analysis is that we can work with non-stationary data, without worrying about cointegration, for the causal analysis, as discussed above. However, obtaining the positive and negative decomposition of the two series, requires us to check for unit roots. The results presented in Table 1, for the unit root test by Im, Pesaran, and Shin (2003) show non-stationarity in levels for both variables but stationarity in their first difference. Therefore the positive and negative components can be derived based on the cumulative sums of the growth rates of the two variables. Tests for cross-sectional dependence (Bresusch and Pagan (1980) test $\left(\mathrm{CD}_{\mathrm{BP}}\right)$, the Lagrange Multiplier test $\left(\mathrm{CD}_{\mathrm{LM}}\right)$ and the Pesaran (2004) test (CD)) and homogeneity (the $\tilde{\Delta}$ and $\tilde{\Delta}_{a d j}$ tests by Pesaran and Yamagata (2008) and a modified version of the Swamy (1970) test proposed by Pesaran and Yamagata (Swamy Shat, 2008)) were also conducted. The tests show that the null hypotheses of no cross-sectional dependence and homogeneity are rejected at a 1 per cent significance level for all the tests. All these results validate the use of our approach which controls for both cross-sectional dependence and heterogeneity, and hence prevents biased results.

Table 1: IPS unit root test results for GDP and tourism receipts for G-7 countries

\begin{tabular}{|l|l|l|l|l|}
\hline & \multicolumn{2}{|c|}{ GDP } & \multicolumn{2}{c|}{ Tourism } \\
\hline & Constant & Constant and trend & Constant & Constant and trend \\
\hline Level & 0.47986 & -0.97052 & 0.95772 & -0.04931 \\
\hline First difference & $-5.43134 * * *$ & $-4.31192 * * *$ & $-7.59943 * * *$ & $-5.76233 * * *$ \\
\hline
\end{tabular}

Notes: Figures denote t-statistics. ${ }^{* * *}$ indicates the rejection of the null hypothesis at the $1 \%$ level.

\footnotetext{
3 The data can be accessed online from: http://databank.worldbank.org/data/reports.aspx?source=worlddevelopment-indicators.

${ }^{4}$ Complete details of these summary statistics are available upon request from the authors.
} 
Table 2: Cross-sectional dependence and Homogeneity tests

\begin{tabular}{|l|l|}
\hline Test & \\
\hline$C D_{B P}$ & $103.351^{* * *}$ \\
\hline$C D_{L M}$ & $12.707^{* * *}$ \\
\hline$C D$ & $6.996^{* * *}$ \\
\hline$\tilde{\Delta}$ & $5.722^{* * *}$ \\
\hline$\tilde{\Delta}_{a d j}$ & $6.180^{* * *}$ \\
\hline Swamy Shat & $248.385^{* * *}$ \\
\hline
\end{tabular}

Note: $* * *$ indicates significance at the $1 \%$ level.

Finally, the results of the symmetric and asymmetric panel causality tests are reported in Table 3. Based on the symmetric version of the test, support for the TLGH is found for Germany, France, and the US. While positive tourism shocks do not seem to matter, negative shocks are found to affect growth negatively for Germany (at $10 \%$ level of significance), Italy and Japan. In other words, for Germany, Italy and Japan, negative tourism shocks are likely to reduce growth, on the (restrictive) assumption that all the other drivers of growth do not change. The results are to some extent understandable, especially for Italy, which does have the highest percentage of contribution from tourism relative to GDP (on average 10.81 percent over the period considered, World Travel and Tourism Council, 2015) compared to all other G7 countries. The weak evidence for Germany is not surprising as travel and tourism contributes to only 4.78 percent of GDP on average over the period under study (World Travel and Tourism Council, 2015). Hence, while Italy should be concerned about declines in tourism receipts and its negative impact on growth, Germany is likely to be less affected. This is not surprising, especially with Germany being technologically advanced to sustain its growth in the wake of a negative shock on tourism, which in turn, is a relatively less important sector of the economy. Japan, is also technologically advanced, and though on average, travel and tourism contributes to 6.48 percentage of the GDP (World Travel and Tourism Council, 2015), it is likely to maintain its growth path in the wake of a decline in tourism receipts. On the whole, our results imply that negative tourism receipts shocks will probably not affect Japan and Germany to the same extent as that of Italy, but under no circumstance can be ignored, especially if the other key drivers of the growth process in these two economies are stagnating for some reason. For UK and the US both negative and positive tourism shocks matter, with the latter having a stronger influence, i.e., increases in tourism receipts on growth increases are likely to outweigh negative impact on growth following decreases in tourism receipts. So, increases in tourism receipts are more important for these two economies, which in general make sense, given the continued importance of these two countries as popular tourist destinations. In addition, given that these economies are welldeveloped and do not rely on tourism alone to maintain its growth process (7.31 (UK) and 8.53 (US) percent of GDP, World Travel and Tourism Council, 2015), our results are also intuitive, as it implies that these two economies are less sensitive to decreases in tourism 
Table 3: The Results of Symmetric and Asymmetric Panel Causality Tests.

\begin{tabular}{|c|c|c|c|}
\hline COUNTERY & $\begin{array}{c}\text { NULL } \\
\text { HYOTHESIS }\end{array}$ & $\begin{array}{c}p \text {-value of } \\
\text { Causality Test }\end{array}$ & $\begin{array}{l}\text { Significant Causal } \\
\text { Parameter Value }\end{array}$ \\
\hline \multirow[t]{3}{*}{ Canada } & $\operatorname{Tr} \neq>Y$ & 0.7294 & \\
\hline & $T r^{-} \neq>Y^{-}$ & 0.3427 & \\
\hline & $T r^{+} \neq>Y^{+}$ & 0.5453 & \\
\hline \multirow[t]{3}{*}{ Germany } & $\operatorname{Tr} \not>Y$ & 0.0294 & 0.119659 \\
\hline & $T r^{-} \neq>Y^{-}$ & 0.0621 & 0.187976 \\
\hline & $T r^{+} \neq>Y^{+}$ & 0.5453 & \\
\hline \multirow[t]{3}{*}{ France } & $\operatorname{Tr} \neq>Y$ & 0.0223 & 0.146301 \\
\hline & $T r^{-} \neq>Y^{-}$ & 0.1317 & \\
\hline & $\operatorname{Tr}^{+} \neq>Y^{+}$ & 0.4089 & \\
\hline \multirow[t]{3}{*}{ Italy } & $T r \neq>Y$ & 0.2038 & \\
\hline & $T r^{-} \neq>Y^{-}$ & 0.0028 & 0.410194 \\
\hline & $T r^{+} \neq>Y^{+}$ & 0.3534 & \\
\hline \multirow[t]{3}{*}{ Japan } & $T r \quad \neq>Y$ & 0.5327 & \\
\hline & $T r^{-} \neq>Y^{-}$ & 0.0446 & 0.140507 \\
\hline & $T r^{+} \neq>Y^{+}$ & 0.3467 & \\
\hline \multirow[t]{3}{*}{ UK } & $\operatorname{Tr} \neq>Y$ & 0.7961 & \\
\hline & $T r^{-} \neq>Y^{-}$ & 0.0977 & 0.133960 \\
\hline & $T r^{+} \neq>Y^{+}$ & 0.0294 & 0.295246 \\
\hline \multirow[t]{3}{*}{ US } & $\operatorname{Tr} \neq>Y$ & 0.0167 & 0.057211 \\
\hline & $T r^{-} \neq>Y^{-}$ & 0.0629 & 0.012269 \\
\hline & $\operatorname{Tr}^{+} \neq>Y^{+}$ & 0.0046 & 0.06770 \\
\hline
\end{tabular}

Note: The denotation $\operatorname{Tr} \neq>$ Y means that real tourism does not Granger cause real GDP in the panel. The optimal lag order in the dynamic model was one in each case. 
receipts relative to when the same increases. So, note that, if we did not disaggregate the tourism shocks into its positive and negative components, and relied only on the symmetric causality test, we would conclude wrongly that TGLH holds only for Germany, France and the US. However, as we see, barring Canada, there is either symmetric or asymmetric or both forms of causality in the remaining six countries. Lack of evidence for Canada regarding the TLGH is perhaps not surprising given that travel and tourism contributes to about 4.83 percentage of GDP (World Travel and Tourism Council, 2015), which though low is higher than Germany.

\section{Conclusion}

Unlike the existing literature on TLGH, we analyse the whether tourism affects growth in an asymmetric fashion for G-7 countries over the period of 1995-2014, using a panel set-up which allows for heterogeneous effects across countries, as well as, controls for crosssectional dependence. Our results reveal that TLGH holds for France, Germany and the US, with negative shocks being more important for Germany, Italy and Japan, while positive shocks are more important than negative shocks in the UK and the US. Our results imply that, policy makers in Germany, Italy and Japan should be more concerned when there are negative shocks to real tourism receipts. In the UK and the US policy makers should want to ensure that real tourism receipts keep rising, so that they fuel the growth process. Tourism in Canada, does not seem to be playing any role in affecting the growth process. Finally, for France TLGH holds in general, with no specific relative importance of the negative and positive shocks. So overall, TLGH holds in some form (symmetric or asymmetric) of the other or both in the six of the G7 countries, which in turn would have been only limited to three, if we had ignored asymmetric Granger causality. However, we must be cautious in drawing strict policy conclusions from our paper, since each G7 economy is well-developed and does not necessarily rely on tourism alone to maintain its growth process. In addition, here the econometric framework, assumes that tourism alone affects growth, which is clearly not the case. As there are other other drivers of growth in these countries, and we need to check for the robustness of the effect of tourism receipts. So in this paper, while we can draw preliminary conclusions regarding the direction of causality, we should not put much emphasis on the size of the effect, which in the absence of other variables are likely to be an overestimate in any event.

In this paper, we were concerned about analysing asymmetric causality and are silent about the dynamics of the effects, i.e., how long the effect lasts, even though we can sign the impact of positive and negative shocks. As part of future analysis, it would be interesting to conduct impulse response analysis to check the time-length of the impact of a tourism shock on the output of the economy. 


\section{References}

Antonakakis, N., Dragouni, M., and Filis, G. (2015a). Time-Varying Interdependencies of Tourism and Economic Growth: Evidence from European Countries. Economic Modelling, 44(C), 142-155.

Antonakakis, N., Dragouni, M., and Filis, G. (2015b). Tourism and growth: The times they are a-changing. Annals of Tourism Research, 50(C), 165-169.

Arslanturk, Y., Balcilar, M., and Ozdemir, Z. A. (2011).Time-varying linkages between tourism receipts and economic growth in a small open economy. Economic Modelling, 28(1), 664-671.

Balaguer, J. and Cantavella-Jorda, M. (2002) Tourism as a Long-run Economic Growth Factor: the Spanish Case, Applied Economics, 34, 877-884.

Balcilar, M., van Eyden, R., Inglesi-Lotz, R., and Gupta, R. (2014). Time-varying linkages between tourism receipts and economic growth in South Africa. Applied Economics, 46(36), 4381-4389.

Breusch, T. S., \& Pagan, A. R. (1980). The Lagrange multiplier test and its applications to model specification in econometrics. The Review of Economic Studies, 47(1), 239-253.

Brida J.G., Cortes-Jimenez I. and Pulina M. (2016) Has the tourism-led growth hypothesis been validated? A literature review, Vol. 19(5), 394-430.

Granger, C.W.J. (1969). Investigating causal relations by econometric models and crossspectral methods. Econometrica, 37: 424-439.

Granger, C.W.J. and Yoon G. (2002). Hidden Cointegration. University of California, Economics Working Paper No. 2002-02.

Gunduz L. and Hatemi-J A, (2005). Is the tourism-led growth hypothesis valid for Turkey? Applied Economics Letters, 12, 499-504.

Hatemi-J, A. (2008). Forecasting properties of a new method to choose optimal lag order in stable and unstable VAR models. Applied Economics Letters, 15(4): 239-243. 
Hatemi-J, A. (2011). Asymmetric Panel Causality tests with an application to the impact of fiscal policy on economic performance in Scandinavia. MPRA Paper No 55527.

Hatemi-J, A., Ajmi, A.N., El Montasser, G., Inglesi-Lotz, R., and Gupta, R. (2016). Research Output and Economic Growth in G7 Countries: New Evidence from Asymmetric Panel Causality Testing. Applied Economics, 48(24), 2301-2308.

Im, K.S., Pesaran, M.S. and Shin, Y. (2003). Testing for unit roots in heterogeneous panels. Journal of econometrics 115 (1): 53-74.

Kónya, L. (2006). Exports and growth: Granger causality analysis on OECD countries with a panel data approach. Economic Modelling, 23: 978-992

Oh, C. (2005) The contribution of tourism development to economic growth in the Korean economy, Tourism Management, 26(1), 39-44.

Pesaran, M. H. H. M. (2004). General diagnostic tests for cross section dependence in panels.

Pesaran, M.H., and Yamagata, T. (2008). "Testing slope homogeneity in large panels". Journal of Econometrics 142:50-93.

Swamy, P. A. (1970). Efficient inference in a random coefficient regression model. Econometrica: Journal of the Econometric Society, 311-323.

Unite Nations World Tourism Organisation. (2015). UNWTO Annual Report.

World Travel and Tourism Council. (2015). Travel and tourism economic Impact. 